
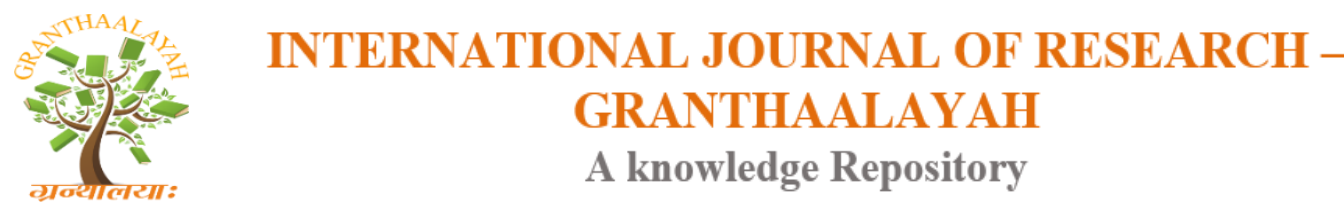

Science

\title{
THE EFFECT OF MIXING ON THE PRODUCTION OF BIODIESEL FROM NEEM SEED OIL USING METHANOL AND HOMOGENEOUS CATALYST
}

\author{
F. Sini ${ }^{1}$, I. M Atadashi ${ }^{1}$ \\ ${ }^{1}$ Department of Chemistry, Faculty of Science, Adamawa State University, Mubi-Nigeria
}

\begin{abstract}
Biodiesel was prepared through alkali-catalysed transesterification of neem seed oil using sodium hydroxide as catalyst and ethanol. This process of was carried out firstly throuch eserification and then via transesterification. The process was carried out by varying stirring speed $(350,450,550$, 650,750 and $850 \mathrm{rpm}$.) and keeping other variables constant (temperature of $60^{\circ} \mathrm{C}$, catalyst concentration of $1 \mathrm{w} / \mathrm{w} \%$ and 6:1 oil to ethanol molar ratio). In this research work, a yield of $93 \mathrm{w} / \mathrm{w} \%$ was achieved at the stirring speed of $850 \mathrm{rpm}$. It was observed that the viscosity $\left(3.73 \mathrm{~mm}^{2} / \mathrm{s}\right.$ at $\left.40^{0} \mathrm{C}\right)$ of neem oil methylester generated was within the limit $\left(2-6 \mathrm{~mm}^{2} / \mathrm{s}\right)$ specified by the American Society for Testing and Materials Standards. The density of neem biodiesel at ambient temperature $\left(25^{\circ} \mathrm{C}\right)$ was found to be $0.85 \mathrm{~g} / \mathrm{ml}$, which is exactly close to the density of diesel $(0.83 \mathrm{~g} / \mathrm{ml})$. The Flash Point of the neem oil biodiesel produced was $153.6^{\circ} \mathrm{C}$ which above the ASTM D6751 minimum standards for biodiesel fuel of $130^{\circ} \mathrm{C}$. Furthermore, Neem oil biodiesel has a pour point of $-4^{0} \mathrm{C}$ and a cloud point of $2^{\circ} \mathrm{C}$. These values clearly indicate that the use of neem oil methyl esters in colder regions is limited. However, this value is also indicative of the high potential of this fuel as biodiesel particularly in Northern Nigeria where temperature is always above $20^{\circ} \mathrm{C}$, a temperature at which the oil is fluid.
\end{abstract}

Keywords: Biodiesel; Neem; Transesterification; Flash Point; Density.

Cite This Article: F. Sini, and I. M Atadashi. (2018). "THE EFFECT OF MIXING ON THE PRODUCTION OF BIODIESEL FROM NEEM SEED OIL USING METHANOL AND HOMOGENEOUS CATALYST.” International Journal of Research - Granthaalayah, 6(9), 451457. https://doi.org/10.5281/zenodo.1464991.

\section{Introduction}

As biodiesel has become alternative to conventional petroleum diesel, much research work on modeling strategies for biodiesel production has been carried out, namely on the development of kinetic models for transesterification reactions [1,2]. Other proposed model is that of Khor et al. [3] for biodiesel production via enzymatic transesterification. It has been experimentally shown for different feedstocks and catalysts that the evolution of the transesterification reaction strongly depends on the applied mixing intensity. Ataya et al. [4] have attested the absence of the acid- 
catalyzed reaction between canola oil and methanol when the two phases are quiescent. Ma et al. [5] have demonstrated the importance of mixing in the base-catalyzed methanolysis of beef tallow. Rashid et al. [6] have studied the effect of the stirring intensity (among other variables) on the evolution of the yield of the transesterification of cotton seed oil for several catalysts. Recently, Sharma et al. [7] have reported a monotonous increase of the reaction yield with the agitation speed until a maximum at which the yield stabilizes. Sharma et al. [7] used karanja oil, a nonedible feedstock rich in free fatty acids, and observed the same yield evolution pattern in experiments with different catalysts. A similar behavior has been pointed out by Lee et al. [8] for enzymatic biodiesel production under supercritical fluid conditions. In their experimental work, Kafuku and Mbarawa [9] have also observed that the conversion efficiency increased with the agitation rate until an optimum. However, since that point on, cavitation phenomena appeared, leading to a decrease in the overall efficiency. A marginal decrease in the yield beyond optimum agitation intensity was also experimentally detected by Rashid et al. [6]. They have attributed that insignificant decrease to attrition of particles, with some of them being thrown out of the reacting mixture, as well as to the shearing of the catalyst. It was confirmed, through the ANOVA analysis, that the correlation between the yield of lipase-catalyzed methanolysis of soybean oil and the agitation speed is indeed significant [8]. Using factorial design of experiments, Berrios et al. [10] have also verified a dependency of the transesterification reaction on the agitation speed for a fixed time of reacting mixture. Alternative mixing techniques have been proposed for biodiesel production, such as the use of ultrasounds [11], static mixers [12], oscillatory flow reactors [4] or centrifugal contactor reactors/separators [10]. However, mechanical stirring remains broadly used in biodiesel production to provide the needed mixing of reactants for the reaction to proceed.

In a system where mixing is achieved with the rotation of a moving element, the degree of mixing obviously depends on its frequency of rotation. However, it depends also on the system geometry, on the fluid physical properties, and on the mixing characteristics [13]. Changing exclusively the volume of the reacting mixer (a geometric parameter of the system), Stamenkovic' et al [14] have obtained distinct dynamic profiles for the transesterification reaction. Frascari et al. [15] have confirmed experimentally different evolutions of the methanolysis of sunflower oil when using different mechanical impellers. Therefore, one can state that for a given reactor, processing certain oil and equipped with a particular impeller, the degree of mixing depends on the stirrer frequency of rotation. Worldwide energy crisis due to depletion of petroleum resources, petroleum price hike and increased environmental problems have led to the search for an alternative biodiesel fuel, which should not only be sustainable but also environment benign. The aim of this research work is to determine the effect of mixing on the production of biodiesel using methanol and homogeneous catalyst.

\section{Materials and Methods}

\subsection{Materials}

The refined Neem Oil was purchased from commercial store. Methanol, Ethanol Propanol and Butanol were of $99.5 \%$ purity, potassium hydroxide, hydrochloric acid, $\mathrm{Na}_{2} \mathrm{SO}_{4}$ were of analytical grade. 


\subsection{Methods}

The overall processing of biodiesel from neem oil consists of the collection of oil from neem seed first. Combined reaction of alcohol, catalyst and oil take place. Crude neem oil when transesterified using $\mathrm{NaOH}$ catalyst produces soaps formation due to saporification side reaction. This is due to the higher level of free fatty acids and quantity of moisture in the crude neem oil. Therefore, a twostep process acid catalysed esterification followed by alkali catalysed transept edification was employed according to the method of [2].

\subsection{Acid pre-treatment (acid-catalysed esterification)}

The crude oil was weighed, heated at $60^{\circ} \mathrm{C}$ for about 10 mins and mixed with $55.8 \mathrm{ml}$ of methanol (60\% w/w of oil). $1.2 \%$ w/w of concentrated $\mathrm{H}_{2} \mathrm{SO} 4$ was added to the mixture. The resulting mixture was then stirred on the magnetic hot plate for $1 \mathrm{hr}$ at $50^{\circ} \mathrm{C}$, after which it was allowed to settle for $2 \mathrm{hrs}$. The pretreated oil was separated from the alcohol-water phase at the top [12].

\subsection{Transterification Process for the Production of Biodiesel}

The transesterification process was carried out using a batch reactor. A stirrer was used to stir the mixture in the screw-capped vessel. The vessel was kept in a water bath to maintain the temperature. The mixture was stirred at a varying speed between $300-600 \mathrm{rpm}$. After the transesterification reaction, the product mixture was poured into a separating funnel and then allowed to settle into two phases. Since ethanol has boiling point of $78.30^{\circ} \mathrm{C}$, higher reaction temperature of $70^{\circ} \mathrm{C}$ was used. As per stoichiometry reaction carried out at $3: 1$ ethanol to oil molar ratio, the reaction is a reversible one, hence, an excess of ethanol was necessary to drive the equilibrium towards ethyl ester formation [3]. Therefore actual experimental tests were carried out at higher molar ratio.

\subsection{Purification of Crude Biodiesel Produced}

After the transesterification is completed, glycerol and methanol was removed from biodiesel mixture, the resulting biodiesel was thoroughly washed using acidified water. The main objective of refining biodiesel using water washing is to remove contaminants such as glycerol, alcohol and soap etc produced during biodiesel production process. In water washing, the added acid usually neutralizes the alkaline catalyst and then breakdown the soap formation. The soap formed usually reacts with the acid to produce salts which are soluble in water and as well free fatty acids. Further during water washing salts are rapidly removed, whereas the free fatty acids remained in the biodiesel. Moreover, purification of biodiesel via water washing affords reduction of free glycerol contents that is ranked among the key important factors to determine if the biodiesel produced meets the biodiesel standard specifications for use in diesel engines. In addition, the phase separation between biodiesel and water is characteristically clean and absolutely complete [5,11]. In each run, the purified biodiesel mixture was transferred to a separatory funnel for the separation of biodiesel from the wastewater. The bottom layer (wastewater) was removed and the biodiesel phase be dried using anhydrous $\mathrm{Na}_{2} \mathrm{SO}_{4}$ (25\% of the amount of the ester product) and then filtered. The upper layer, containing the refined biodiesel product, was then stored and prepared for analysis. 


\subsection{Characterization of Biodiesel Based on their Physical Properties}

The biodiesel to be produced was characterized for its physical properties such as density, viscosity, cloud point, pour point, flash point and cetane number. The properties of the biodiesel were measured using mainly the American Society for Testing and Materials (ASTM, 1980). The Physical properties of biodiesel to be determined according to the standard test methods are shown in Table 1.

\section{Results and Discussions}

\subsection{Results}

Biodiesel was produced via the transesterification of neem seed oil via alkaline catalyzed mechanism. The reaction conditions includes; reaction time of 60 minutes, temperature of $60^{\circ} \mathrm{C}$, catalyst concentration of $1 \% \mathrm{w} / \mathrm{w}$ homogeneous sodium hydroxide. The effect of mixing speed on the conversion rates was observed. Mixing speed was varied between 350, 450, 550, 650, 750 and 850 revolutions per minute (rpm).

\subsubsection{FT-IR Spectra of Neem Seed Oil}

The FT-IR spectra in the mid-infrared region have been used to identify functional groups and the bands corresponding to various stretching and bending vibrations in the samples of oil and biodiesel. The position of carbonyl group in FT-IR is sensitive to substituent effects and to the structure of the molecule. The FTIR spectra of oil allowed to identify the typical bands of vegetable oils such as the one located at $1100-1170 \mathrm{~cm}$ correspondent to the vibrations of the $\mathrm{C}-\mathrm{CH}-\mathrm{O}$ group, the asymmetric stretching of $\mathrm{C}-\mathrm{O}-\mathrm{C}$ and $\mathrm{C}-\mathrm{C}$ bond stretching. The intense peak located at $1748.66 \mathrm{~cm}-1$ corresponds to the carbonyl radical and is characteristic of the esters. The band at $2859.2 \mathrm{~cm}$ was due to the symmetric stretching of $\mathrm{CH}(-\mathrm{CH}-)$ and at $2929.92 \mathrm{~cm}$ that was correspondent to the asymmetric stretch of $\mathrm{CH}(-\mathrm{CH}-)$ saturated bonds that are abundant in vegetable oil [12] (Figure 1).

\subsubsection{Effect of Mixing Speed on The Yield of Biodiesel Produced Via the Transesterificaion of Neem Seed Oil.}

From the Figure 1 and Table 2, the percentage yield of the biodiesel significantly increases as the mixing speed is increased from $350 \mathrm{rpm}$ to 650 . A rather uniform small increase was observed as the mixing speed was increases through 850rpm. Agitation speed plays an important role in the formation of end product (mono alkyl ester or biodiesel), because agitation of oil and catalyst mixture enhances the reaction. Lower stirring speed encourages lower product formation. On the other hand higher stirring speed favors formation of soap. This is due to the reverse behaviour of transesterification reaction [5].

\subsection{FT-IR Spectra of Biodiesel from Neem Seed Oil}

To confirm the conversion of the fatty acid functional group into an ester, FT-IR analysis was conducted on the biodiesel produced. The FT-IR spectra of the neem biodiesel have confirmed the 
conversion of the triglycerides to mono alkyl esters (biodiesel). The two intense peaks at 2928.89 and $2862.25 \mathrm{~cm}^{-1}$ corresponding to a $\mathrm{CH}$ - strectch I found in both the oil and the biodiesel. However, the ester functional group seen in the oil is converted into methyl ester functional group in the biodiesel. This functional group transformation has confirmed the formation of biodiesel, as the major functional group is the methyl ester.

\subsection{Properties of Biodiesel Produced}

\subsubsection{Kinematic Viscosity}

A gradual decrease in viscosity was observed in the crude neem seed oil and its methylesters with temperature. The result agrees with theoretical claims which opine that viscosity decreases with an increase in temperature. It was observed that the viscosity $\left(3.73 \mathrm{~mm}^{2} / \mathrm{s}\right.$ at $\left.40^{\circ} \mathrm{C}\right)$ of neem oil methyl ester generated was within the limit $\left(2-6 \mathrm{~mm}^{2} / \mathrm{s}\right)$ specified by the American Society for Testing and Materials Standards (2003). Table 3 showed a drastic reduction in viscosity as the fatty acids of the crude neem oil are been concerted into biodisel. The potential of vegetable oils to be used as fuel substitute in diesel engines have been envisaged right from the advent of diesel engines, however, due to its high viscosity such oils are transesterified in order to reduce the viscosity [5]. the biodiesel produced has a viscousity far below the minimun decribed by ASTM D445 and D874, 2007. This goes to show that the biodiesel produced from neem oil under the above conditions had enhanced fluidity as fuel for diesel engines. The kinematic viscosities of biodiesel obtained at various temperatures are within the range specified by ASTM $\left(1.9-6 \mathrm{~mm}^{2} / \mathrm{S}^{2}\right)$.

\subsubsection{Density}

The density of diesel oil is important because it gives an indication of the delay between the injection and combustion of the fuel in a diesel engine (ignition quality) and the energy per unit mass [5]. The density of neem biodiesel at ambient temperature $\left(25^{\circ} \mathrm{C}\right)$ was found to be $0.85 \mathrm{~g} / \mathrm{ml}$, which is exactly close to the density of diesel $(0.83 \mathrm{~g} / \mathrm{ml})$. This shows the potential use of neem seed oil biodiesel as an alternative fuel.

\subsubsection{Flash Point}

One of the most important characteristics of any fuel is its flash point. Flash point is the temperature that indicates the overall flammability hazards in the presence of air; higher flash points make for safe handling and storage of biodiesel [12]. The Flash Point of the neem oil biodiesel produced was $153.6^{\circ} \mathrm{C}$ which above the ASTM D6751 minimum standards for biodiesel fuel of about $130^{\circ} \mathrm{C}$. This makes the biodiesel sample safe for use and storage [5]. Fuels with lower flash point which tend to ignite at lower temperatures are highly dangerous if not stored and used properly. Most non-edible based seeds oils flash point are higher than fossil diesel [7].

\subsubsection{Pour and Cloud Point Point}

The pour point is the lowest temperature at which the oil/fuel sample can flow. This property is related to the use of biodiesel in colder region [5]. Neem oil biodiesel has a pour point of $-4^{0} \mathrm{C}$ and a cloud point of $2^{0} \mathrm{C}$. These values clearly indicate that the use of neem oil methyl esters in colder 
regions is limited. However, this value is also indicative of the high potential of this fuel as biodiesel particularly in Northern Nigeria where temperature is always above $20^{\circ} \mathrm{C}$, a temperature at which the oil is fluid.

\section{Conclusions and Recommendations}

\subsection{Conclusion}

Neem seed oil was transesterified with ethanol in the presence of homogenous sodium hydroxide catalyst at a reaction temperature of $60^{\circ} \mathrm{C}$, while maintaining a steady reaction time of 60 minutes, the mixing speed was varied between $350,450,550,650,750$ and $850 \mathrm{rpm}$. From the results obtained, the following conclusions were made: The flash point of $153.6^{\circ} \mathrm{C}$ indicated that the biodiesel is within the specification of ASTM. Also, the high value of flash point indicated that the oil is safe for handling as it exceeds the minimun ASTM requirement (93min). Furthermore FT-IR analysis was employed to determine biodiesel formed.

\subsection{Recommendation}

1) More research should be done on the potential of neem seed oil to serve as a viable substitute for fossil diesel.

2) Public sensitization should be done to educate the populace about the potentials of some of the seed or feedstock in their closest environment to serve as raw materials for biodiesel production.

3) The government of Nigeria should work towards the industrial production of biodiesel for commercialization. This would help boost the economy and avoid many problems associated with petroleum.

\section{References}

[1] Bambase, M., Nakamura, N., Tanaka, J., Matsumura, M., 2007. Kinetics of hydroxidecatalyzed methanolysis of crude sunflower oil for the production of fuel-grade methyl esters. Journal of Chemical Technology and Biotechnology 82, 273-280. doi:10.1002/jctb.1666.

[2] Berchmans, H.J., Morishita, K., Takarada, T., 2010. Kinetic study of methanolysis of Jatropha curcas-waste food oil mixture. Journal of Chemical Engineering of Japan 43, 661-670 <http://www.jstage.jst.go.jp/article/jcej/43/8/43_661/_article>.

[3] Khor, G.K., Sim, J.H., Kamaruddin, A.H., Uzir, M.H., 2010. Thermodynamics and inhibition studies of lipozyme TL IM in biodiesel production via enzymatic transesterification. Bioresource Technology 101, 6558-6561. doi:10.1016/ j. biortech.2010.03.047.

[4] Ataya, F., Dub'e, M.A., Ternan, M., 2007. Acid-catalyzed transesterification of canola oil to biodiesel under single- and two-phase reaction conditions. Energy and Fuels 21, 2450-2459. doi:10.1021/ef0701440.

[5] Ma, F., Clements, L.D., Hanna, M.A., 1999. The effect of mixing on transesterification of beef tallow. Bioresource Technology 69, 289-293. doi:10.1016/S0960- 8524(98)00184-9.

[6] Rashid, U., Anwar, F., Knothe, G., 2009. Evaluation of biodiesel obtained from cottonseed oil. Fuel Processing Technology 90, 1157-1163. doi:10.1016/ j. fuproc.2009.05. 016.Reyes, J., Malverde, P., Melin, P., Bruijn, J.D., 2010. Biodiesel production in a jet flow stirred reactor. Fuel 89, 30933098. doi: 10.1016/j.fuel.2010.06.002. 
[7] Sharma, Y.C., Singh, B., Korstad, J., 2010. High yield and conversion of biodiesel from a nonedible feedstock (Pongamia pinnata). Journal of Agricultural and Food Chemistry 58, 242-247. doi:10.1021/jf903227e.

[8] Lee, J., Kwon, C., Kang, J., Park, C., Tae, B., Kim, S., 2009. Biodiesel production from various oils under supercritical fluid conditions by Candida antartica lipase using a stepwise reaction method. Applied Biochemistry and Biotechnology 156, 454-464. doi:10.1007/s12010-008-84885.

[9] Kafuku, G., Mbarawa, M., 2010. Biodiesel production from Croton megalocarpus oil and its process optimization. Fuel 89, 2556-2560. doi:10.1016/ j. fuel.2010.03.03

[10] Berrios, M., Gutiérrez, M., Martín, M., Martín, A., 2009. Application of the factorial design of experiments to biodiesel production from lard. Fuel Processing Technology, 90 1447-1451. doi: 10.1016/j.fuproc.2009.06.026.

[11] Ji, J., Wang, J., Li, Y., Yu, Y., Xu, Z., 2006. Preparation of biodiesel with the help of ultrasonic and hydrodynamic cavitation. Ultrasonics 44, e411 - e414. In: Proceedings of Ultrasonics International (UI'05) and World Congress on Ultrasonics (WCU). doi: 10.1016/j.ultras.2006.05.020.

[12] Thompson, J.C., He, B.B., 2007. Biodiesel production using static mixers. Transactions of the ASABE 50, 161-165 <http://asae.frymulti.com/ abstract.asp?aid=22389\&t=2>.

[13] Hemrajani, R., Tatterson, G.B., 2004. Mechanically Stirred Vessels. Handbook of Industrial Mixing. John Wiley \& Sons (Chapter 6), pp. 345-390.

[14] Stamenkovic', O.S., Todorovic', Z.B., Lazic', M.L., Veljkovic', V.B., Skala, D.U., 2008. Kinetics of sunflower oil methanolysis at low temperatures. Bioresource Technology 99, 1131-1140. doi: 10.1016/j.biortech.2007.02.028.

[15] Frascari, D., Zuccaro, M., Paglianti, A., Pinelli, D., 2009. Optimization of mechanical agitation and evaluation of the mass-transfer resistance in the oil transesterification reaction for biodiesel production. Industrial and Engineering Chemistry Research 48, 7540-7549. doi:10.1021/ie900283j.

*Corresponding author.

E-mail address: atadashimusa1@ yahoo.com 